\title{
Qualitative risk analysis framework for office developments
}

\author{
Nisa Zainudeen, Jeyarajah Jeyamathan
}

\begin{abstract}
Property investment always carry significant amount of risks and uncertainties. Risk management is not much trendy practice within property developers in Sri Lanka. Risk analysis is important to realize the impact of risks and how it affects financial aspects of the developer if occurred. This research facilitates the developers to identify what are the potential risks that could occur during development and post development stages of office developments. This will further assist them in order to make decisions on alternative solutions and/or to reserve necessary funds so as to cope with risks in an effective manner by providing prior knowledge of potential risks. Identification of probable risk factors has been accomplished via semi structured interviews reinforced by findings of the literature survey. Identified risk factors in development and post development stages of office developments have been qualitatively analyzed applying a risk matrix considering the overall impact of risks in terms of significance and probability. The analysis reveals that the overall impact of risk is not very high in both office property development and management. Furthermore the risks during post development stage are lesser than at development stage. It was further revealed that most of the risks could be reduced or eliminated by means of proper planning, executing and regular monitoring in terms of consequence and/or likelihood of occurrence of risk factors.
\end{abstract}

\section{Introduction}

The property market can be arrangements of buyers and sellers of offices \& shops houses, virgin land, agricultural and industrial buildings which are brought together to agree on a price at which the particular property can be exchanged. Property investment is always dealt with risks since most of the investment decisions are made regarding the future. Property development is a process of enhancing the value of real estate by making physical changes and improvements thereto through the application of capital and entrepreneurial skill by a property developer. In economic terms property market is said to be imperfect or inefficient due to its heterogeneous nature and inadequacy of available information. Consequently investing in such a market always carries significant amount of risks and uncertainties. The conditions that economics assume to be necessary for a perfect market are that there should be many buyers, many sellers, a homogeneous product and full information (Evans, 2004).

Property development as a commercial activity is generally found in the urban sector, and covers a wide range of activities varying from real estate transactions to land sub division for residential, commercial or industrial development purposes. The economic significance and social importance of property is immense. Property development produces a chain of economically connected activities in construction, manufacturing, trading, professional services and finance. The relationship between the property market and the wider economy is of particular significance for a number of reasons. First, the property market plays an important role in the economy of the country. In the banking sector, most domestic credit currently comprises mortgage loans for property development. Changes in property prices and rents influence consumer price inflation, and effect competitiveness as a service-based economy. Secondly, property prices tend to be more volatile in SriLanka with anumber of large swings in the past two decades [Zainudeen and Ramachandra, 2006]. Therefore its impact upon national development issues such as unemployment and its contribution to economic growth can be considerable. Rodney and Venmore-Rowland (1996) has stated that the inputs to the development process are numerous and some will be relatively certain prior to the commencement of the development, while others will be uncertain and likely to vary over the development period. The uncertainty of these variables fundamentally gives property development its unique characteristics. Some of the unique features of property investment that distinguishes property from other form of investment are as follows: heterogeneous in nature, decentralized market, impractical to know real market price, significant amount of risk involved in investment decisions, certain inherent problems in property management, low liquidity and provides a hedge against inflation [James and staney, 1999] 
Therefore consideration should be paid to develop strategies to reduce the effect of risk during property development. Just allowing contingency and insuring the property is not sufficient. By this developers can survive or can cover the costs or just earn something but it won't allow gaining maximum return out of it. Risk management is not a popular strategy among many developers in Sri Lanka. Unknown to them this attracts many inconvenience and downsides to their investments. Issues like benefits of risk management need to be addressed in order to overcome this problem.

Risk is defined as the identification, measurement and control at the most economic cost of the hazard, which can threaten the assets and the earnings of the organization [Aimah and Aini, 2000]. Several researches have been done on risks in property development in recent past. According to Olusegun, et.al. (2005), development appraisal papers worldwide increasingly incorporate an emphasis on risk analysis. Therefore risk management in development projects is timely and pertinent to discuss.

In growth of an economy the commercial sector plays a vital role. The Colombo Metropolitan Region is the most developed region in the country contributing to $45 \%$ of Gross Domestic Product (GDP) (Cesma International Pte Ltd, 2003). On this context multi storied office development in Colombo Metropolitan Region will become more significant in near future. This paper explores a risk management framework for investors of office property in Colombo city.

\section{Background: Risks inherent in property development and management}

By its nature property investment will carry significant amount of risk compared to other types of investments. In Sri Lankan context generally 3-4 months period is needed to acquire planning permissions depending on the type of the property, type of the local authority and how the project will influence on environmental and other regulations etc. of the country. Delays in getting approvals will subsequently delay the developers' schedules and increase the land holding period of pre development that directly affects the developers' profit. Other risk factors include complexity, speed of construction, and familiarity with the work. When serious risks occur on a project the effects can be very damaging. In extreme cases, time and cost overruns turn a potentially profitable project into a loss making venture. Unexpected physical characteristics of land would initiate several impacts such as design changes, changes in construction duration and budget and so on. Depending on the situation this can lead to significant changes in developers' expectations. Especially for commercial property location is paramount aspect that influences the demand for the property. While office buildings located at the heart of the Western Region has very high demand, buildings located away from the commercial hub may have risk of disposal of the property. Availability of better infrastructure facilities and other services is also significant in selecting suitable tenants to lease the property. Tenants in commercial properties seek prominent location and facilities, ease of access and are concerned of the characteristics of neighborhood.

Greaves (1998) has stated that the use of borrowed money is normal in property development and financial risk arises when a mixture of equity and debt capital finances an investment. In the financial sector interest rates are extremely volatile with wide margins of variations in short periods of time. Unavailability of finance at the right time would lead to long pre development period which straightforwardly influence on developers profits. Rise and fall of economic cycle of the country will have an impact on every sector of the economy. Usilappan (1993) states that property is subject to cyclical changes and property values are not always on an ever increasing trend. Therefore, a clear understanding of the characteristics of property, its ever changing values and the forces that impose upon it is vital for a developer. In the Srilankan context, a recent research proves that using Gross Domestic Products and capital formation economic indicators of property markets, the up and down turns of property economic cycles take the similar features of the construction economic cycle [Ramachandran. and Zainudeen, 2006].

A market is said to be efficient if prices therein reflect quickly and truthfully all public information about the economy. As the information of the market is not readily available, a new investor may find more difficulties in making investment decisions. This fact might initiate considerable amount of risk on development appraisal. Competitors at the market are also an important issue that developers encounter in property development. It could provide various difficulties for new developers to stabilize in the market. Further it may lead to selection of unsuitable tenants that could cause greater troubles during the operation and management period. According to Greaves (1986, p.38), political risks arise from unstable governments and these risks are usually judged in terms of how long the government will last, with some taking the view that a long-standing government is a stable government. In Sri Lankan context 6 years of government ruling period cannot be considered as stable enough in terms of property investment. Besides, political instability can arise if a government is thus forced to change its attitude towards major issues such as taxation, private or public entrepreneurialship or its policies in the land and property market.

Even very basic leases normally require a landlord to insure against fire and explosion. More modern documents extend the range of insurance obligations to make specific reference to damage by terrorist activity. Today in Sri Lanka terrorist risk is a critical factor in 
commercial property specially those located in Pettah and Kolpity areas. The increase of terrorist risk will lead to high premium charges on insurance. Therefore the security situation of the country highly affects the developers' expectations. According to Dent and White (1998), several surveys published more recently (Connaught Report, 1997; Howlandand Lindsay, 1997; Wadsworth, 1996) examine the ability of existing office provision to meet the needs of the changing market. Howland and Lindsay's work tracks the origins of occupiers in new buildings and the destination of those from older buildings. Wadsworth's research suggests that selection of office space is based more on utility than design or prestige. The need for flexibility is obvious in the rapidly changing configurations of power and communication networks. Operational stage may itself carry significant portion of risk especially in multi tenanted buildings. Major risk that developers encounter is rent collection. Apart from this operational cost, building maintenance and lease management might carry considerable amount of risk at this stage. Robinson (1999) noted that lack of fully informed market causes decision-making difficulties in respect of leased premises, particularly when establishing the specifically commercial components of the lease. The most commercial components of a lease are those components relating to the payment of rent and increases in rent during the lease term.

\section{Research aim and methodology}

The aim of this paper is to identify and analyze the risks in large-scale Office Development projects (more than 6 storeys in Colombo Metropolitan area) in Srilanka and there by formulate a framework to identify and classify inherent risks in office development projects.

A detail literature review was done in order to examine the general background of property market and its associated risks. Semi structured interviews with project managers of property development projects were carried out to identify the risk drivers such as location and size of property. Face-to- face interviews were conducted with ten project managers with 20 minutes mean time from the construction sites and head office. During the interview, each interviewee was asked for information, opinions and insights based on an identical set of questions. Readable version of interview transcripts was developed through manual transcribing. The interview outcomes of each case study were analyzed by means of content analysis technique, using the software program NUD*IST Vivo produced by QSR for coding function . Code-based content analysis was used since it enables to find similar cognitions under a particular concept and considers its meanings rather than the actual content of the segment which can be found in interview transcripts in each case (Senaratne, 2005). Questionnaires were distributed among the developers of medium to large scale for twenty projects (more than six stories); to inves- tigate the nature of impact and frequency of risk affected their projects. The questionnaire comprised of two parts; risk during the development stage and the post development stage [occupation stage].Through this method, it was probable to find the significance and likelihood of risk factors. Analysis of the identified risk factors was done through qualitative risk analysis techniques in order to formulate a qualitative risk analysis framework that can assist decision makers in identifying and classifying risks.

\section{Risk analysis techniques}

Property development is always beset with risk and uncertainties. Therefore proper techniques should be applied to assess the risks effectively. Risk analysis techniques can be qualitative, semi-quantitative or quantitative. Generally quantitative techniques are complex in their nature, consume more time to perform the analysis and some times requires expert knowledge to perform the analysis. Lichtinstein (1996) in his research has revealed that the selection of risk assessment technique mainly depends on seven significant factors such as usability, creditability, complexity, completeness, adaptability, validity and cost of risk assessment method. Their selection would depended on the project type, size, complexity, level of information available, the cost involved and the time available for the exercise (Hamimah \& Aini, 2000). Strutt (1993 c) gives the fullest definition of risk analysis in a third paper where he sets out the concept in seven stages as follows:

Systematic assessment (item by item question every part of the system)

Identification of risks ( local and global scale)

Assessment of risks (frequencies and consequences). This may involve a number of different analysis.

Establish acceptable or tolerable levels of risk

Evaluation of Risk. Are the risks acceptable? Can they be reduced and at what cost?

Determine whether the risks are as low as reasonably practicable.

Determine risk reduction measures where appropriate.

Qualitative risk analyzing techniques includes but not limited to: Risk registers, Risk check lists, Hazard and operability studies (HAZOPS), Failure modes effects analysis (FMEA) and Failure modes and effects criticality Analysis (FMECA), SWOT Analysis, What-if analysis, Fault tree analysis (FTA), Event tree analysis (ETA), Preliminary hazard analysis (PHA), Risk factor analysis (RFA) and Risk ranking matrix (RRM). All the techniques mentioned above were pri- 
marily initiated for the purpose of different systems and industries. But the concept of above discussed techniques can successfully apply to the property market. This research was executed using qualitative risk analysis techniques. The reasons behind selection of qualitative risk analysis techniques namely (1) Risk checklists and (2) Risk ranking methods are discussed below.

According to Michael and Budnick (2002), Risk checklists are typically qualitative in nature. That is, they will not provide quantitative risk assessment, but rather will document the existence of particular risk factors. Procedure for performing a checklist analysis consists of the following steps.

1. Define the activity or system of interest

2. Define the problems of interest for the analysis

3. Subdivide the activity or system for analysis

4. Gather or create relevant checklists for the prob lems of interest

4. Respond to the checklist questions

6. Further subdivide the elements of the activity or system (if necessary or otherwise useful)

7. Use the results in decision-making (Source: USCG, 2001)

The benefits of this type of risk assessment are that they are tailored to a specific project, workplace, or task type; used to identify higher priority jobs in terms of ergonomics concerns; usually fast, simple to administer, and easy to understand; do not require special equipment or tools.

Limitations of the techniques are that the structure of checklist analysis relies exclusively on the knowledge built into the checklists to identify potential problems; a checklist will not comprehensively evaluate a work area, and usually provide little assistance in controlling identified concerns; most checklist reviews produce only qualitative results. Rink Ranking /Risk Matrix are techniques that can help to identify, prioritize, and manage key risk factors that could affect the successful delivery of a project, on time, within budget, and that meet user requirements. There are two main dimensions to risks: (a) How likely they are to occur and (b) The Impact that they would have, if they occur.

Likelihood and consequences are defined in terms of particular activities. The risk matrix simply puts probability and Impact on two sides of an $x-y$ chart and then the risks are placed within this two-dimensional space. A common way of quantifying the risk is to assign a numeric value to these and to multiply these together (Australian Agency for International Development, 2005).A risk matrix can either be, qualitative, semi-quantitative or quantitative which can be changed to fit the risk environment. The qualitative matrix is useful for screening purposes using words most people understand when knowledgeable indi- viduals apply common sense (Barringer \& Associates, 2004). More complicated semi-quantitative risk matrix as an intermediate level requires more questions and more analysis to avoid overly conservative risk ranking which may occur with the qualitative risk matrix (Barringer \& Associates, 2004). Finally the matrix grows to the third level for a quantitative risk matrix with specific failure probability scales for the vital few items that are worthy of the increased attention and costs. This requires establishing criteria for probability of failure and the cost consequences for the matrix.

The benefits of this type of risk assessment are that they follow the process in an unemotional manner to control risks; used as a communication tool and helps to do the right thing for the right reason. Limitations of the techniques are that the high-probability/ low-impact risks get the same score as high-impact/ low-probability risks, about that may well has very different view.

\section{Data analysis}

Impact of the Risk: The impact of a risk can be determined by the probability of occurrence and consequence of the risk factor if it would occur. The relationship can be described by the following equation. The two variables, Consequence and the Likelihood have been classified by qualitative terms in this study. Impact $=$ Consequence $\mathrm{x}$ Likelihood

Consequences of Risk: Risk Consequence measures the severity of adverse affects, or the magnitude of a loss, if the risk comes to pass. Table 3.1 illustrates the classification of risk consequences used in the survey.

Table 3.1: Classification of consequences of risks in office developments

\begin{tabular}{|l|l|}
\hline \multicolumn{1}{|c|}{$\begin{array}{c}\text { Risk } \\
\text { Consequences }\end{array}$} & \multicolumn{1}{c|}{ Description } \\
\hline Critical & $\begin{array}{l}\text { If the risk event occurs, the development project } \\
\text { may have to terminate or discontinue. }\end{array}$ \\
\hline Severe & $\begin{array}{l}\text { If the risk event occurs, the development project } \\
\text { may continue. But other objectives such as } \\
\text { predicted profit margin, time schedules and quality } \\
\text { requirements etc. may not be met. }\end{array}$ \\
\hline Moderate & $\begin{array}{l}\text { If the risk event occurs, some of the objectives may } \\
\text { not be met. }\end{array}$ \\
\hline Minor & $\begin{array}{l}\text { If the risk event occurs, most of the objectives may } \\
\text { be met }\end{array}$ \\
\hline Negligible & $\begin{array}{l}\text { If the risk event occurs, it will have no effect or } \\
\text { negligible effect on the development or operation of } \\
\text { the building. }\end{array}$ \\
\hline
\end{tabular}

Table 3.2: Likelihood of risk factors in office developments

\begin{tabular}{|l|l|l|}
\hline \multicolumn{1}{|c|}{ Likelihood } & \multicolumn{2}{|c|}{ Description } \\
\hline Very Likely & $>80 \%$ & $\begin{array}{l}\text { The risk event will occur more than 5 times } \\
\text { during the lifetime of the project. }\end{array}$ \\
\hline Likely & $\begin{array}{l}\text { Between } \\
80 \%-60 \%\end{array}$ & $\begin{array}{l}\text { The risk event will occur 4-5 times during the } \\
\text { lifetime of the project. }\end{array}$ \\
\hline Occasionally & $\begin{array}{l}\text { Between } \\
60 \%-40 \%\end{array}$ & $\begin{array}{l}\text { The risk event will occur 2-3 times during the } \\
\text { lifetime of the project. }\end{array}$ \\
\hline Unlikely & $\begin{array}{l}\text { Between } \\
40 \%-20 \%\end{array}$ & $\begin{array}{l}\text { The risk event will occur only once in the } \\
\text { lifetime of the project. }\end{array}$ \\
\hline Very Unlikely & $<20 \%$ & The risk event will never occur. \\
\hline
\end{tabular}


Likelihood of the Risk: Likelihood is the probability that an event will actually occur. Risk likelihood ratings have been formulated using the criteria given in table 3.2.

\section{Risk ranking scale}

Weightings had been given for each consequence and likelihood so as to analyze data. The weightings are given in the table 3.3 and table 3.4. Then using the above mentioned equation, impact of each identified risk factor was calculated.

Table 3.3: Weightings for consequences of the risk

\begin{tabular}{|l|c|}
\hline \multicolumn{1}{|c|}{$\begin{array}{c}\text { Risk } \\
\text { Consequences }\end{array}$} & Weightage \\
\hline Critical & 5 \\
\hline Severe & 4 \\
\hline Moderate & 3 \\
\hline Minor & 2 \\
\hline Negligible & 1 \\
\hline
\end{tabular}

Risk Consequences Weightage

Table 3.4: Weightings for likelihood of the risk

\begin{tabular}{|l|c|}
\hline \multicolumn{1}{|c|}{ Likelihood } & Weightage \\
\hline Very Likely & 5 \\
\hline Likely & 4 \\
\hline Occasionally & 3 \\
\hline Unlikely & 2 \\
\hline Very Unlikely & 1 \\
\hline
\end{tabular}

Identification of Risk Drivers: Annex B explains several risk factors in office property development that have been identified through interviews. The risk factors were then classified according to development and post development stages of office property developments.

During the interview and survey it was found that most of the risk factors were dependant on the location and size of the property drivers. Location of the property has a huge influence over other risk factors. Depending on the location factors such as rules and regulations, market conditions, physical conditions of the land, availability of services etc. could be changed. Therefore different development projects would come across different levels of risk in different areas even within Colombo Metropolitan Region. This dissimilarity can be perceived in areas for exclusive office developments (e.g. Nawam Mawatha) and in areas of mixed developments (e.g. Fort, Union Place, Kolpity).
Size of the building is another significant element which regulates the extent of risk that different projects would encounter. Size of the building can be explained in many ways for instance total floor area, number of stories, and number of units to be rented out etc. Depending on the size of the building some rules and regulations, risks related to construction, risks related to tenant management etc. could change. For instant nature and the degree of risk imposed on large scale buildings like WTC and HNB tower would differ from small scale buildings like Millennium House or Green Lanka Tower at Nawam Mawatha. Due to the influence of these two factors on risks, they have been considered as risk drivers and the other risk factors have been analyzed within the frame work of these two factors.

Classification of risk factors according to the risk drivers

Classification According to the Location of Property: Two distinct types of locations were identified by comparing locations of twenty office development project selected, as given in table 3.5 with illustrations. Office developments located at Nawam Mawatha and Ramanayake Mawatha were classified under location 1 category. For the location 2 category office buildings located in Fort, Union Place, Kolpity were selected. From the 20 projects, 10 projects were classified into location 1 category while other 10 projects were classified under location 2 Category.

Table 3.5: Categorization according to Location

\begin{tabular}{|c|l|}
\hline Location & \multicolumn{1}{|c|}{ Description } \\
\hline Location 1 & $\begin{array}{l}\text { Locations of exclusive office developments (Considered area: Nawam } \\
\text { mawatha, Ramanayake mawatha) }\end{array}$ \\
\hline Location 2 & $\begin{array}{l}\text { Locations of mixed developments such as commercial, residential etc } \\
\text { (Considered areas: Kolpity, Fort, Union Place) }\end{array}$ \\
\hline
\end{tabular}

Classification According to Size of the Building: Three categories of building size were identified as shown in table 3.6. The categorization was done by thoroughly analyzing the data collected. Since the size of the building cannot be explained using a single characteristic, three conditions were established; floor area, height and number of units. Out of the twenty projects, 4 projects were classified under Class $A$ while 8 projects were classified under Class $B$ the other 8 projects were considered under Class $C$ category.

Having at least two of the conditions set out in table 3.6 is considered as requirements in classifying the buildings in to the relevant categories.

Table 3.6: Categorization according to Building Size

\begin{tabular}{|l|l|l|l|l|}
\hline CONDITIONS & CLASS A & CLASS B & CLASS C \\
\hline Condition 1 & Floor Area & $\begin{array}{l}\text { More than 10,000 } \\
\text { m2 }\end{array}$ & $\begin{array}{l}1000 \mathrm{~m} 2- \\
10,000 \mathrm{~m} 2\end{array}$ & $\begin{array}{l}\text { Less than 1000 } \\
\text { m2 }\end{array}$ \\
\hline Condition 2 & Height & $\begin{array}{l}\text { More than 20 } \\
\text { Stories }\end{array}$ & $11-20$ Stories & $6-10$ Stories \\
\hline Condition 3 & $\begin{array}{l}\text { Number of } \\
\text { Units }\end{array}$ & $\begin{array}{l}\text { More than 50 } \\
\text { Units }\end{array}$ & $10-50$ Units & $\begin{array}{l}\text { Less than 10 } \\
\text { Units }\end{array}$ \\
\hline
\end{tabular}


The next step of the analysis is to evaluate the risks in a comparable form. Relative importance index ranking was selected as the methodology for this. For this purpose total value of risk impact derived from the weightings using the survey data of each category for each risk factor were transformed into relative important indices (RII) using the well-established RII ranking technique.

\section{$\Sigma W$}

Relative Important Index $(\mathrm{RII})=$

Where,

$$
\overline{\mathrm{A} \times \mathrm{N}}
$$

$\mathrm{W}=$ Weight given to each factor by the respondents (range from 1-25)

$A=$ Highest weight $(25)$

$\mathrm{N}=$ Total number of projects

Ranking of Risk Factors: Using RII ratings risk factors were classified into five different categories as shown in the table 3.7. The purpose of the categorization is to provide a straightforward and clear view of the degree of the risk. The benefits of the established risk ranking matrix are; simple to use and understand, does not require extensive knowledge of quantitative risk analysis techniques, have clear guidance on applicability, have consistent likelihood ranges that cover the full spectrum of potential scenarios, have detailed descriptions of the consequences of concern for each consequence range, provide clear guidance on what action is necessary to mitigate scenarios with intolerable risk levels.

Table 3.7: Ranking and categorization of risk factors

\begin{tabular}{|l|l|}
\hline RII & RISK CLASS \\
\hline $80 \%$ and above & Very High \\
\hline $60 \%-80 \%$ & High \\
\hline $40 \%-60 \%$ & Moderate \\
\hline $20 \%-40 \%$ & Low \\
\hline Less than $20 \%$ & Negligible \\
\hline
\end{tabular}

Risk Responses Strategy: With reference to the Risk Ranking Matrix, a Risk Action Plan was developed. Based on the given risk action plan (Refer table 3.8), risk response strategies for the risk factors during development and post development stages were formulated.

\section{Table 3.8: Risk Action Plan}

\begin{tabular}{|l|l|}
\hline Risk Class & Risk Response Strategy \\
\hline Very High & Avoid the Risk \\
\hline High & Finance the Risk \\
\hline Moderate & Manage the Risk (Plan risk reduction) \\
\hline Low & Accept or Transfer the Risk \\
\hline Negligible & Ignore \\
\hline
\end{tabular}

The illustrations for the above formulated strategies are given below;

\section{Avoid the Risk: Eliminate the risk producing activityentirely.}

2. Finance the Risk: Provision of funds to meet the cost of risk.

3. Manage the Risk: Objectives of this strategy are to:

- Reduce the probability of occurrence

- Reduce the magnitude of loss

- Change the consequences of the risk

4. a. Accept the Risk: Acceptance of the possible risk and associated Loss/benefit of gain.

b. Transfer the Risk: Shift some of the financial bur den of a loss to another party

5. Ignore: For the time being it is negligible and can be ignored.

\section{Research findings}

Impact of the risk factors has been analysed according to the location and size of the building in above tables. In Development Stage how the developers should respond when they come across, risk is imperative for project success. Annex A provides a framework of strategies for development stage according to size and location they should develop in order to handle the situation successfully and to gain maximum return out of it. One limitation of this risk matrix is since only NDB building is in location 1-class A category it represents some biased results.

When the impact of the risk is very high it is wise to avoid such risks rather than trying to financing it. According to the results no such risk are found in the development stage. In some cases financing the risk is the best solution in order to gain more return as it says 'more risk means more return' (E.g. cost of construction). Many risks can be reduced or eliminated by means of proper management and also mitigation in the form of planning, exercising and regular monitoring of them (e.g. delays in construction, availability of finance). Occasionally some risks are less significant, but may cause upset and inconvenience in the short term. For that reason consideration should be paid to minimize the effect by means of basic planning and monitoring or transferring risks to an insurance company. When the occurrence of risk brings least impact to the project it can be accepted or disregarded.

No risk factors having 'very high' or 'high' impact during the post development stage. Rise and fall of economic cycle and inflation are having 'moderate' im- 
pact, which is the highest in this stage. Long lease periods, operational risk, capital on maintenance, political changes and development of regulations are risk factors with 'low' impact. Rent collection, re-letting and changes in occupier needs are having 'very low' impact and do not differ location wise. But these risks are much higher ('low') in class A type buildings. Selection of suitable tenants is having 'low' impact in both locations. In class B type buildings it is 'very low' since it would be easy to find tenants suit for both rental and building condition. In both locations rent reviews is having 'low' impact. But it is 'moderate' in class A type buildings perhaps due to its complex lease structure and more tenants whose having different lease periods subsequently create difficulties in executing alterations. Other natural disasters are having 'low' impact. But in class C type of buildings it is 'very low' may be due to the less consequence of risk compared to larger size buildings. Terrorist risk in location 2 and class $B$ buildings is high, since importance of location and building is respectively higher in two situations and subsequently the possibility of terrorist attacks is also high.

Compared to the development stage developers would encounter less risks in post development stage. However management of risks is important during the post development or the occupation stage to ensure economic viability. Specially in changing economic and inflationary situations consideration should be paid in order to minimize the effects and to identify alternative measures to lessen the consequence. Another option is risk can be transferred to tenants through rentals (e.g. operational risks, capital on maintenance etc.) and to insurance corporations (e.g. terrorist risk, other natural disasters etc.).

The main objective of the study is to develop a framework for risks in office development. From the findings of analyzing the twenty projects, two separate frameworks for development and post development stages have been formulated as given in Annexes $A$ and $B$ respectively. These frameworks can be useful for developers who envisage to invest in office property to have a quick notion about the likely risks and the degree of their significance. A thorough scrutiny of these frameworks reveals some interesting and important findings. One key finding is that there are no risks in the "High Risk" category. Cost overruns in construction seem the comparative high risk among all risk factors identified in both stages.

\section{Conclusions}

Many qualitative risk analysis techniques are available such as discussed in this paper that can be easily utilized for the purpose. They are easy to apply and understand, simple, less time consuming, lowpriced and do not require specialized knowledge. In office developments comparatively overall impact of risk appears to be less since risks having 'very high' impacts was not found through the research. On the whole construction cost is having the highest impact over other risk factors in office developments. If such a risk occurs strategic measures should be taken to treat it. It is always safe for the developer to reserve necessary funds so as to cope cost overruns if occur during construction. As delays in construction and availability of finance also have considerable amount of impact more efforts should be made to bring down these risks during the construction period. Moreover that risk during post development stage is lesser than at development stage and almost all the risks can be minimized or eliminate by means of proper management of risk. Risk management will not remove all risks from a project but it will ensure that risks are managed in the most efficient manner. Some other important conclusions from this study could be summarized as follows.

(a) Since re-letting has 'very low' impact, that will reflect the demand for office property on prevailing market condition. This is a welcome issue for new developers entering the market. (b) Despite the fact that in literature rent collection is expected to be a note worthy issue, in real situation it does not seem to be the case. This reflects that in Sri Lanka landlord - tenant relationship is maintaining in a better position (c) Regarding changes in occupier needs, the situation does not seem to have significant risks, as most developers do not expect major deviations of consumer preference during occupation though this is a considerable issue in many other countries like UK. (d) Since selection of suitable tenants is not much risky, which again reflects the prevailing demand for office buildings in the market (e) Proper management of lease will ultimately reduce many risks as the lease agreement is the only fallback to both parties when there is a dispute.

Special concern on terrorist risk has been given through out the study because the survey was carried out during the time period having high security threats within the country. It could be concluded that the developer's attitude towards risk is a significant issue since it effects how he handles situations if risk has occurred. Analyzing risks in office property development had exposed that most of the risks can be managed by means of basic planning and regular monitoring by developers themselves. It can also be stated that the risks associated with office development in the Colombo Metropolitan region is not very high at present, and is likely to remain the same in the foreseeable future. 


\section{References}

\section{Australian agency for international develop} ment, (2005) "Ausguildline. Austra lia," Available from: http:// www. ausaid.gov.au/ausguide/pdf/ ausguideline6.3.pdf [accessed 30 November 2007]

Barringer \& Associates, (2004) "Risk based deci sions," Available from: http://www. Barrin ger1. com/nov04prb_files/filelist.xml [ac cessed 15 august 2007]

\section{Center for Chemical Process Safety (CCPS),} (2004) "Guidelines For hazard evaluation procedures: second edition," Available From: http://www.amazon.com [accessed $21 \mathrm{Sep}$ tember 2007]

Cesma International Pte Itd, (2003) Regional struc ture plan of the western region megapolicy, Sri Lanka.

Dent $\mathbf{P}$ and White A, (1998) "Corporate real estate: changing office Occupier needs-a case study Facilities," 16(9), 262-270. Available from: http://www.emeraldinsight.com [ac cessed 1 October 2007]

Evans A.W, (2004) Economic, real estate and the supply of land, 1st ed. London: Blackwell Sci ence Itd.

Greaves M.J, (1998) "Risk in property manage ment," The Malaysian Surveyor: Malaysia, $37-46$

Hamimah A and Aini J, (2000) "The role of the proj ect manager in Managing risks in the con struction of a mega project: a case study," The Malaysian surveyor: Malaysia, 18-24

James B and Staney, MSG, (1999) Cities in the Pa cific Rim: planning systems and property markets, London: e and fn spon
Lichtinstein S, (1996) "Factors in the selection of a risk assessment Method. Information man agement \& computer security," 4(4), 20-25. Available from:http://www.emeraldinsight. com [accessed 9 September 2007]

Michael R and Budnick P, (2002) "Using checklists to evaluate Risk factors [online]," Available from: http://www.ergoweb.com/news/detail. cfm [accessed 16 February 2007]

Olusegun A.O, Olatoye O. and Terry P.B, (2005) Assessing Development appraisal risk with reference to client specific risk Tolerance and perspectives. In: a.c.sidwell, ed. Qut re search week 2005, 4-5 July 2005 Australia: Queensland university of technology

Robinson J, (1999) "Commercial lease term and the property cycle. Facilities,"17(5), 177186. Available from: http://www.emeraldin sight.com [accessed 7 august 2007]

Rodney B and Venmore-rowland P, (1996) Private versus Public sector property development projects: risk evaluation techniques, UK: RICS research

Senaratne S, (2005) A knowledge-based approach to managing project change in the construc tion phase with collaborative team settings, Thesis (phd). UK: Salford university.

Ramachandra T, Zainudeen N, (2006) "The relation ship between Sri Lankan property market," Built Environment: Sri Lanka, 7: 1-10 United States Coast Guard, (2001) "Risk based decision making Guideline," Available from: http://www.uscg.mil/hq/gm/risk/e-guide lines [accessed 21 october 2007]

Usilappan M, (1993) "Property risk analysis in bank lending," The Malaysian surveyor, Malaysia: 30-37 
Annex A: Risk management framework for development stage according to size and location

\begin{tabular}{|c|c|c|c|c|c|c|}
\hline \multirow[t]{2}{*}{ Risk Factors At Development Stage } & \multicolumn{3}{|c|}{ Location 1} & \multicolumn{3}{|c|}{ Location 2} \\
\hline & Class A & Class B & Class C & Class A & Class B & Class C \\
\hline Cost of construction & Finance the Risk & Finance the Risk & Finance the Risk & Finance the Risk & Finance the Risk & Finance the Risk \\
\hline Delays in construction & Finance the Risk & Manage the Risk & Manage the Risk & Manage the Risk & Manage the Risk & Manage the Risk \\
\hline $\begin{array}{l}\text { Nature \& extent of use local authority will } \\
\text { permit }\end{array}$ & Finance the Risk & Manage the Risk & Manage the Risk & Manage the Risk & Manage the Risk & Manage the Risk \\
\hline Availability of finance & Manage the Risk & Manage the Risk & Manage the Risk & Manage the Risk & Manage the Risk & Manage the Risk \\
\hline Rise and fall of economic cycle & Accept the Risk & Manage the Risk & Manage the Risk & Manage the Risk & Manage the Risk & Manage the Risk \\
\hline Terrorist risk & Transfer the Risk & Transfer the Risk & Transfer the Risk & Manage the Risk & Manage the Risk & Transfer the Risk \\
\hline Capital cost & Transfer the Risk & Transfer the Risk & Transfer the Risk & Manage the Risk & Transfer the Risk & Transfer the Risk \\
\hline Physical characteristics of land & Manage the Risk & Transfer the Risk & Transfer the Risk & Transfer the Risk & Transfer the Risk & Transfer the Risk \\
\hline BOI concessions & Manage the Risk & Accept the Risk & Accept the Risk & Accept the Risk & Accept the Risk & Accept the Risk \\
\hline Availability of services & Transfer the Risk & Transfer the Risk & Transfer the Risk & Transfer the Risk & Transfer the Risk & Transfer the Risk \\
\hline Government rules and regulations & Accept the Risk & Accept the Risk & Accept the Risk & Accept the Risk & Accept the Risk & Accept the Risk \\
\hline Timely approvals & Accept the Risk & Accept the Risk & Accept the Risk & Accept the Risk & Accept the Risk & Accept the Risk \\
\hline Changes in interest rates & Accept the Risk & Accept the Risk & Accept the Risk & Accept the Risk & Accept the Risk & Accept the Risk \\
\hline Land holding period of pre development & Transfer the Risk & Transfer the Risk & Transfer the Risk & OK for Now & Transfer the Risk & Transfer the Risk \\
\hline Changes in government & Accept the Risk & Accept the Risk & Accept the Risk & OK for Now & Accept the Risk & Accept the Risk \\
\hline Changes in consumer preference & Transfer the Risk & Transfer the Risk & OK for Now & Transfer the Risk & Transfer the Risk & Transfer the Risk \\
\hline Competitors & Transfer the Risk & Transfer the Risk & OK for Now & Transfer the Risk & Transfer the Risk & Transfer the Risk \\
\hline Period for letting & Transfer the Risk & OK for Now & OK for Now & Transfer the Risk & Transfer the Risk & Transfer the Risk \\
\hline Acts of God & Transfer the Risk & Transfer the Risk & OK for Now & Transfer the Risk & Transfer the Risk & OK for Now \\
\hline Advertising cost & OK for Now & OK for Now & OK for Now & OK for Now & OK for Now & OK for Now \\
\hline Professional fees & OK for Now & OK for Now & OK for Now & OK for Now & OK for Now & OK for Now \\
\hline Legal cost & OK for Now & OK for Now & OK for Now & OK for Now & OK for Now & OK for Now \\
\hline
\end{tabular}

\section{Annex B: Risk management framework for post development stage according to size and location}

\begin{tabular}{|c|c|c|c|c|c|c|}
\hline \multirow{2}{*}{ Risk Factors At Post Development Stage } & \multicolumn{3}{|c|}{ Location 1} & \multicolumn{3}{|c|}{ Location 2} \\
\hline & Class A & Class B & Class C & Class A & Class B & Class C \\
\hline Rise and fall of economic cycle & Manage the Risk & Manage the Risk & Manage the Risk & Manage the Risk & Manage the Risk & Manage the Risk \\
\hline Inflation & Manage the Risk & Manage the Risk & Manage the Risk & Manage the Risk & Manage the Risk & Manage the Risk \\
\hline Terrorist risk & Manage the Risk & Transfer the Risk & Transfer the Risk & Finance the Risk & Manage the Risk & Manage the Risk \\
\hline Rent reviews & Manage the Risk & Transfer the Risk & Transfer the Risk & Manage the Risk & Transfer the Risk & Transfer the Risk \\
\hline Selection of suitable tenants & Manage the Risk & OK for Now & Accept the Risk & Accept the Risk & Accept the Risk & Accept the Risk \\
\hline Long lease periods & Manage the Risk & Transfer the Risk & OK for Now & Transfer the Risk & Transfer the Risk & Transfer the Risk \\
\hline Operational risks & Manage the Risk & Transfer the Risk & OK for Now & Transfer the Risk & Transfer the Risk & Transfer the Risk \\
\hline Capital on maintenance & Manage the Risk & Transfer the Risk & OK for Now & Transfer the Risk & Transfer the Risk & Transfer the Risk \\
\hline Political changes & Accept the Risk & Accept the Risk & Accept the Risk & Accept the Risk & Accept the Risk & Accept the Risk \\
\hline Development of regulations & Accept the Risk & Accept the Risk & Accept the Risk & Accept the Risk & Accept the Risk & Accept the Risk \\
\hline Other natural disasters & Transfer the Risk & Transfer the Risk & OK for Now & Transfer the Risk & Transfer the Risk & Transfer the Risk \\
\hline Changers in occupier needs & Transfer the Risk & Transfer the Risk & OK for Now & OK for Now & OK for Now & OK for Now \\
\hline Re-letting & Accept the Risk & OK for Now & OK for Now & OK for Now & OK for Now & OK for Now \\
\hline Rent collection & Accept the Risk & OK for Now & OK for Now & OK for Now & OK for Now & OK for Now \\
\hline
\end{tabular}

